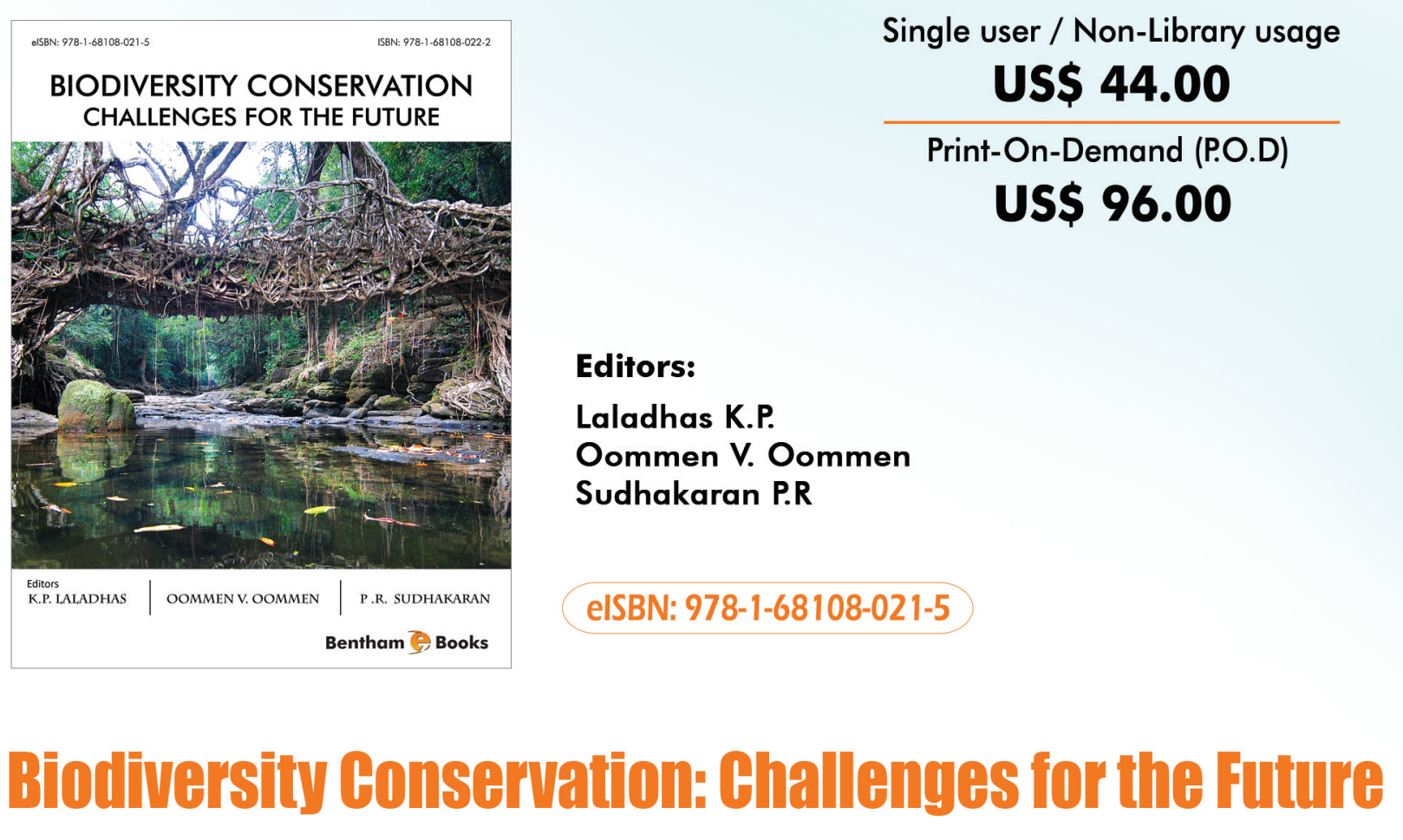

\title{
Ww. Ehooks.henthamseience.com/hook/9781681080215
}

\section{About the eBook}

Biodiversity Conservation - Challenges for the Future is a handy resource for the local (Indian) conservationist community consisting of policy makers, academicians, scientists, environmentalists, students and grass root level conservationists.

\section{Contents}

...a beacon of hope for the future of biodiversity in India...

Foreward by Balakrishna Pisupati

Former Chairman, National Biodiversity Authority, India

The Diversity and the Ecological Status of Snakes in Kerala Region-A View to Prioritize Conservation Measures

- Conservation of Medicinal Plant Resources through Community Born Biodiversity Management Committee, Kerala, India

- The State of Frogs in India: A Case for Discontinuation of Use of Frogs in Dissections and Experiments

- The Role of People's Participation in the Conservation and Management of Biodiversity and Associated Traditional Knowledge

Current and Likely Trends in Biodiversity Conservation

- Natural Bioresources of North Eastern Region of India - Its Conservation and Proper Utilization

For Advertising Inquiries: Contact: marketing@benthamscience.org 